\title{
ANALISIS KEBUTUHAN E-MODUL FISIKA SEBAGAI BAHAN AJAR BERBASIS PBL DI MA MUSLIMAT NU
}

\author{
Iva Malina ${ }^{1}$, Hadma Yuliani ${ }^{2}$, Nur Inayah Syar $^{3}$ \\ ivamalinaa@gmail.com \\ ${ }^{1,2}$ Program Studi Tadris (Pendidikan) Fisika, IAIN Palangka Raya, Palangka Raya, Indonesia
${ }^{3}$ Program Studi Pendidikan Guru Madrasah Ibtidayah, IAIN Palangka Raya, Palangka Raya, Indonesia
}

Received: 2 Juni 2021

Revised: 4 Juni 2021

Accepted: 16 Juni 2021

\begin{abstract}
This research was conducted to develop a learning resource of the type of learning media in the form of PBL-based teaching materials. Thus, research requires a preliminary study consisting of literature studies and field studies. The type of research conducted is descriptive qualitative research. The data collection instruments of this research were in the form of interview sheets for teacher needs analysis, and student needs analysis questionnaires. The teaching materials developed are in the form of electronic modules (e-modules) that can contain text, images, and learning videos, as an independent learning effort that is systematically arranged. To create an e-module using the Flip PDF Professional application. Needs analysis was conducted to find out the learning resources used by the teacher, the obstacles during the learning process, and the learning resources needed by the students. The results of the analysis of the needs of 44 students of class XI science obtained that $95.5 \%$ had a handbook for studying physics, however, $77.3 \%$ of students in the static fluid material in the handbook were difficult to understand. So according to 52.3\% of students the handbook used is not sufficient as a learning resource and $95.5 \%$ of students need other learning resources to support learning activities and $93.2 \%$ of students need other learning resources that can be understood independently. These results indicate the need to develop teaching materials in the form of e-modules based on PBL static fluid materials.
\end{abstract}

Keywords: Needs Analysis, Teaching Materials, Learning Media, PBL (Problem Based Learning), (E-modul) Electronic Module

\begin{abstract}
Abstrak: Penelitian ini dilaksanakan untuk mengembangkan suatu sumber belajar jenis media pembelajaran berupa bahan ajar berbasis PBL. Sehingga, penelitian diperlukan studi pendahuluan yang terdiri atas studi literatur dan studi lapangan. Jenis penelitian yang dilakukan adalah penelitian deskriptif kualitatif. Instrumen pengumpulan data penelitian ini berupa lembar wawancara analisis kebutuhan guru, dan angket analisis kebutuhan peserta didik. Bahan ajar yang dikembangkan berupa (e-modul) modul elektronik yang dapat memuat teks, gambar, serta video pembelajaran, sebagai upaya belajar mandiri yang disusun secara sistematis. Untuk membuat e-modul menggunakan aplikasi Flip PDF Professional. Analisis kebutuhan dilakukan untuk mengetahui sumber belajar digunakan guru, kendala saat pembelajaran berlangsung, dan sumber belajar diperlukan peserta didik. Hasil analisis kebutuhan 44 peserta didik kelas XI IPA diperoleh 95,5\% memiliki buku pegangan untuk belajar fisika akan tetapi, 77,3\% peserta didik materi fluida statis di dalam buku pegangan sulit dipahami. Sehingga menurut 52,3\% peserta didik buku pegangan yang digunakan belum mencukupi sebagai sumber belajar dan 95,5\% peserta didik membutuhkan sumber belajar lain untuk menunjang kegiatan belajar serta 93,2\% peserta didik membutuhkan sumber belajar lain yang dapat dipahami secara mandiri. Hasil tersebut menunjukkan perlunya dikembangkan bahan ajar berupa e-modul berbasis $P B L$ materi fluida statis.
\end{abstract}

Kata Kunci: Analisis Kebutuhan, Bahan Ajar, Media Pembelajaran Fisika, PBL (Problem Based Learning), (E-modul) Elektronik modul

Puplished at https://ojs.stkippgri-lubuklinggau.ac.id/index.php/SJPIF 


\section{PENDAHULUAN}

Abad ke-21 menuntut setiap orang untuk menguasai ilmu pengetahuan dan teknologi (IPTEK). Pada abad ini, semua aktifitas kehidupan tidak terlepas dari teknologi. Untuk berkomunikasi dibutuhkan alat komunikasi yang merupakan produk teknologi komunikasi. Untuk melakukan perjalanan dibutuhkan alat transfortasi yang merupakan produk teknologi transfortasi. Untuk membangun tempat tinggal dibutuhkan alat konstruksi dan bahan bangunan yang merupakan produk teknologi konstruksi. Serta masih banyak lagi aktifitas kehidupan lainnya yang semuanya memanfaatkan teknologi. Teknologi tidak serta-merta muncul dengan sendirinya, teknologi membutuhkan ilmu pengetahuan sebagai dasarnya. Untuk menguasai IPTEK dibutuhkan sumberdaya manusia yang berkualitas yang dapat bertidak secara cepat, tepat, kreatif, dan inovatif. Oleh karena itu, pendidikan memiliki peranan penting untuk menciptakan sumber daya manusia yang berkualitas tersebut. Pendidikan merupakan pintu bagi umat manusia untuk menguasai ilmu pengetahuan dan teknologi. Tanpa pendidikan umat manusia akan buta, ibarat berjalan dimalam yang gelap tanpa cahaya yang menerangi (Sasmita, P. R., \& Hartoyo, Z, 2020).

Pendidikan adalah bentuk aktivitas dan usaha manusia, untuk menumbuhkan potensi diri melalui pembelajaran (Azhar \& Sa'idah, 2017). Pembelajaran adalah upaya terencana agar terjadinya proses belajar, sehingga tingkah laku peserta didik menjadi lebih baik (Arfani, 2016). Peserta didik dalam kegiatan pembelajaran tidak hanya berinteraksi dengan guru sebagai salah satu sumber belajar, tetapi juga berinteraksi dengan semua sumber belajar yang mungkin dipergunakan untuk memperoleh hasil yang ingin dicapai. Untuk menunjang kegiatan pembelajaran, peserta didik membutuhkan sumber belajar agar dapat memahami pembelajaran (Supriadi, 2015). Berdasarkan Depdiknas (2008) diperoleh bahwa sumber belajar dapat disajikan dalam berbagai bentuk seperti tempat atau kondisi lingkungan, orang, dan fakta yang sedang terjadi. Salah satu sumber belajar yang dapat digunakan oleh guru ialah bahan ajar (Depdiknas, 2008).

Globalisasi adalah proses dimana semua aspek kehidupan manusia akan berkembang secara langsung maupun tidak langsung. Dampak nyata dari perkembangan tersebut adalah bidang pendidikan (Purwoko, Nugraheni, \& Nadhilah, 2020). Di era globalisasi, pendidikan dengan ilmu pengetahuan dan teknologi (IPTEK) sangat erat kaitannya, serta mempengaruhi perkembangan inovasi bahan ajar. Inovasi pengembangan bahan ajar adalah (e-modul) modul elektronik. E-Modul adalah buku berbentuk soft file yang dapat dibuka dan dibaca oleh peserta didik dimana pun dan kapan pun (Andani \& Yulian, 2018). Selain itu, e-modul 
berupa tampilan informasi yang dapat dibaca melalui komputer dalam format buku yang disajikan secara elektronik (Wijayanto \& Zuhri, 2014). E-modul dapat membantu peserta didik agar lebih paham materi yang sedang dipelajari (Ambarsari, 2016), memberikan peserta didik kesempatan berkompetisi, mengekplorasi dan berprestasi (Ristanto, 2011).

Salah satu pelajaran yang membutuhkan bahan ajar berupa (e-modul) modul elektronik adalah fisika. Fisika adalah ilmu sains dan pada dasarnya kumpulan pengetahuan, cara berpikir, dan penyelidikan. Ilmu sains yang dimaksud adalah ilmu yang mempelajari sifat dan gejala pada benda-benda di alam yang dialami oleh alat indra (Fitriani, Gunawan, \& Sutrio, 2017). Proses kegiatan belajar mengajar fisika kerap sekali dihadapkan pada sebuah materi yang abstrak. Pelajaran fisika masih terkesan sulit untuk dipahami karena memiliki konsep yang abstrak dan tidak mudah dihubungkan dengan kejadian seharihari dalam kehidupan manusia. Hal ini menuntut para pendidik untuk kreatif dalam menciptakan dan mengembangkan media-media pembelajaran agar siswa dapat lebih tertarik dalam mempelajari fisika dan materi yang disampaikan dapat benar-benar dimengerti oleh peserta didik (Miswati, M., Amin, A., \& Lovisia, E, 2020).

Fisika merupakan pelajaran yang mengandalkan kemampuan berhitung, bernalar, dan logika yang baik. Oleh karena itu, peserta didik dituntut untuk memahami konsep-konsep fisika secara terarah. Dengan melakukan hal tersebut, diharapkan peserta didik memiliki kemampuan beralasan, berkomunikasi, memecahkan masalah dan menggunakan fisika dalam kehidupan sehari-hari (Hartini, T. I., \& Martin, M, 2020). Permasalahan fisika sering kita jumpai dalam kehidupan sehari-hari. Oleh karena itu, fisika berperan penting untuk dapat melatih peserta didik agar menguasai pengetahuan, konsep, dan prinsip fisika serta menguasai keterampilan ilmiah dan proses (Sukiminiandari, Budi, \& Supriyati, 2015). Permasalahan yang ada dalam ilmu fisika juga terkait dengan permasalahan tentang alam dan gejalanya (Trianggono, 2017). Pemahaman setiap peserta didik berbeda. Sebagian peserta didik ada yang telah memiliki pemahaman yang sesuai dengan prinsip, teori, dan hukumhukum fisika, namun banyak juga yang memiliki pemahaman yang tidak sesuai (DiSessa, 1993).

Untuk membuat e-modul salah satu caranya adalah dengan menggunakan aplikasi Flip PdF Professional. Flip PDF Professional adalah pembuat flipbook kaya fitur yang memiliki fungsi edit halaman yang dapat membuat halaman buku yang interaktif dengan memasukkan multimedia seperti gambar, video, audio, hyperlink, dan lain-lain. Aplikasi Flip PDF Professional memiliki banyak kelebihan, yaitu karena tampilannya yang menyenangkan 
sehingga dapat menarik perhatian peserta didik (Nurcahyono \& Kustijono, 2019), mudah untuk digunakan karena dapat dioperasikan bagi pemula (Seruni, Munawaroh, Kurniadewi, \& Nurjayadi, 2019). Flip PdF Professional dapat menggabungkan file pdf yang berisi materi dengan gambar maupun video pembelajaran (Watin \& Rudy, 2017).

Pada penelitian yang akan dilaksanakan yaitu mengembangkan media pembelajaran berupa bahan ajar yang ditujukan berbasis online. Oleh karena itu, diperlukan penelitian studi pendahuluan yang terdiri atas studi literatur dan studi lapangan. Studi literatur bertujuan untuk mengumpulkan informasi dan menentukan apa saja yang dilakukan dalam kegiatan pembelajaran, sedangkan studi lapangan bertujuan untuk mengetahui kondisi pembelajaran di sekolah. Hal ini sejalan dengan penelitian Arizal Fadli, Suharno, A. A Musadad bahwa studi lapangan dilakukan dengan mengumpulkan berbagai informasi seperti analisis kebutuhan guru dan peserta didik terhadap bahan ajar atau media pembelajaran untuk mengetahui kondisi lapangan (Fadli, Suharno, \& Musadad, 2017). Tujuan dari penelitian ini diharapkan untuk mengetahui sumber belajar digunakan guru, kendala saat pembelajaran berlangsung, dan sumber belajar diperlukan peserta didik.

\section{METODE PENELITIAN}

Jenis penelitian yang dilakukan adalah penelitian deskriptif kualitatif yang dilaksanakan pada 21 Desember 2020. Pada penelitian ini, metode awal dilakukan observasi terhadap teoriteori pendukung dilakukannya penelitian pengembangan ini. Teori serta penelitian terdahulu yang dicari yaitu terkait dengan pengembangan e-modul fisika sebagai bahan ajar berbasis PBL, serta teori pendukung materi fisika yaitu materi fluida statis yang akan dibahas dalam produk pengembangan. Pada pelaksanaan studi lapangan, sampel yang digunakan sampel jenuh. Subjek penelitiannya adalah peserta didik kelas XI MA Muslimat NU Palangka Raya yang berjumlah 44 peserta didik serta guru 1 orang. Metode penelitian ini adalah metode penelitian deskriptif. Instrumen pengumpulan data penelitian ini berupa lembar wawancara analisis kebutuhan guru, angket analisis kebutuhan peserta didik. Analisis data yang dilakukan berupa analisis data kualitatif serta analisis data kuantitatif dari hasil angket. Anget ditulis berbentuk Skala Likert dengan instrumen berbentuk check list. Persamaan yang digunakan yaitu:

$$
\text { Persentase hasil }=\frac{\text { Jumlah peserta didik yang menjawab }}{\text { Total } \text { keseluruhan peserta didik }} \times 100 \%
$$




\section{HASIL DAN PEMBAHASAN}

Berdasarkan analisis kebutuhan guru saat observasi pada saat wawancara diperoleh data sebagaimana tercantum pada tabel 1. Data hasil angket yang disebarkan kepada peserta didik terkait kendala dan bahan ajar yang diperlukan di cantumkan dalam tabel 2 dan 3 .

\section{Hasil dan Pembahasan Kebutuhan Guru}

Analisis kebutuhan guru terhadap media pembelajaran dilakukan melalui proses wawancara dengan pedoman wawancara sebagai berikut:

1. Apa saja bahan ajar yang ibu gunakan selama proses pembelajaran?

2. Apa alasan ibu memilih bahan ajar tersebut?

3. Setelah menggunakan bahan ajar tersebut, bagaimana kemampuan para peserta didik?

4. Bagaimana pendapat ibu mengenai buku pegangan peserta didik dari aspek penampilan dan kelengkapan informasinya?

5. Apakah ibu sebelumnya pernah menggunakan bahan ajar berbasis aplikasi atau menggunakan aplikasi selama proses pembelajaran?

6. Bagaimana pendapat ibu tentang elektronik modul (e-modul)?

Tabel 1. Analisis kebutuhan guru saat observasi

\begin{tabular}{cl}
\hline NO & \multicolumn{1}{c}{ Analisis Pertanyaan } \\
\hline 1. & Buku paket dan LKS \\
2. & Alasan memilih bahan ajar tersebut karena setelah penjelasan dari guru dengan \\
& LKS peserta didik dapat diberi latihan sambil menjawab soal juga serta terdapat \\
& pembahasan latihan-latihan soal yang terdapat di dalam LKS. \\
3. & Setelah penjelasan biasanya ada beberapa peserta didik yang paham, selain itu \\
& ada beberapa peserta didik juga yang perlu bimbingan lebih lanjut karena \\
& memang untuk pelajaran fisika tidak semua anak bisa cepat menangkap. \\
4. & Cukup menarik dan lumayan lengkap \\
5. & Pernah, menggunakan aplikasi path \\
6. & Menurut Ibu, e-modul bisa jadi pilihan yang bagus juga, karena dari segi visual \\
& bisa lebih menarik dibandingkan buku atau yang berbentuk cetak \\
\hline
\end{tabular}

\section{Hasil dan Pembahasan Kebutuhan Peserta Didik}

Berdasarkan hasil sebaran angket pra-penelitian kepada 44 peserta didik kelas XI MA Muslimat NU Palangka Raya, diperoleh hasil yang secara rinci tertera pada tabel 2. Puplished at https://ojs.stkippgri-lubuklinggau.ac.id/index.php/SJPIF 
Tabel 2. Hasil angket analisis kebutuhan peserta didik

\begin{tabular}{|c|c|c|c|c|c|}
\hline \multirow[t]{2}{*}{$\mathrm{NO}$} & \multirow[t]{2}{*}{ Pernyataan } & \multicolumn{2}{|c|}{ Frekuensi } & \multicolumn{2}{|c|}{ Persentase } \\
\hline & & $\mathrm{Ya}$ & Tidak & $\mathrm{Ya}$ & Tidak \\
\hline 1. & $\begin{array}{l}\text { Peserta didik dan guru memiliki buku } \\
\text { pegangan untuk belajar fisika }\end{array}$ & 42 & 2 & $95,5 \%$ & $4,5 \%$ \\
\hline 2. & $\begin{array}{l}\text { Peserta didik menyenangi pembelajaran } \\
\text { dengan adanya media }\end{array}$ & 35 & 9 & $79,5 \%$ & $20,5 \%$ \\
\hline 3. & $\begin{array}{l}\text { Buku pegangan yang digunakan belum } \\
\text { mencukupi sebagai sumber belajar }\end{array}$ & 23 & 21 & $52,3 \%$ & $47,7 \%$ \\
\hline 4. & $\begin{array}{l}\text { Materi fluida statis yang terdapat dalam } \\
\text { buku pegangan sulit dipahami }\end{array}$ & 34 & 10 & $77,3 \%$ & $22,7 \%$ \\
\hline 5 & $\begin{array}{l}\text { Peserta didik membutuhkan sumber } \\
\text { belajar lain untuk menunjang kegiatan } \\
\text { belajar }\end{array}$ & 42 & 2 & $95,5 \%$ & $4,5 \%$ \\
\hline 6. & $\begin{array}{l}\text { Peserta didik membutuhkan sumber } \\
\text { belajar lain yang dapat dipahami secara } \\
\text { mandiri }\end{array}$ & 41 & 3 & $93,2 \%$ & $6,8 \%$ \\
\hline 7. & $\begin{array}{l}\text { Peserta didik belum pernah menggunakan } \\
\text { (e-modul) elektronik modul }\end{array}$ & 30 & 14 & $68,2 \%$ & $31,8 \%$ \\
\hline 8. & $\begin{array}{l}\text { Peserta didik ingin tahu dan mencoba } \\
\text { belajar menggunakan (e-modul) elektronik } \\
\text { modul }\end{array}$ & 42 & 2 & $95,5 \%$ & $4,5 \%$ \\
\hline
\end{tabular}

Tabel 3. Analisis angket kebutuhan peserta didik

\begin{tabular}{cc}
\hline NO & \multicolumn{1}{c}{ Analisis Pernyataan } \\
\hline 1. & $95,5 \%$ peserta didik memiliki buku pegangan untuk belajar fisika \\
2. & $79,5 \%$ peserta didik menyenangi pembelajaran dengan adanya media \\
3. & Menurut $52,3 \%$ peserta didik buku pegangan yang digunakan belum \\
& mencukupi sebagai sumber belajar. \\
4. & Menurut 77,3\% peserta didik materi fluida statis yang terdapat dalam buku \\
& pegangan sulit dipahami \\
5. & $95,5 \%$ peserta didik membutuhkan sumber belajar lain untuk menunjang \\
\hline
\end{tabular}


kegiatan belajar.

6. $93,2 \%$ peserta didik membutuhkan sumber belajar lain yang dapat dipahami secara mandiri.

7. $68,2 \%$ peserta didik belum pernah menggunakan (e-modul) elektronik modul

8. $95,5 \%$ peserta didik ingin tahu dan mencoba belajar menggunakan (e-modul) elektronik modul

Dari hasil analisis angket kebutuhan peserta didik pada tabel 3 terlihat bahwa peserta didik memiliki buku pegangan untuk belajar fisika, namun materi fluida statis yang terdapat pada buku pegangan sulit untuk dipahami sehingga buku pegangan yang digunakan belum mencukupi sebagai sumber belajar. Peserta didik membutuhkan sumber belajar lain untuk mendukung kegiatan pembelajaran, serta membutuhkan sumber belajar yang dapat dipahami secara mandiri. Sumber belajar yang disusun secara sistematis yang dapat dipahami secara mandiri berupa bahan ajar (e-modul) modul elektronik yang dapat memuat teks, gambar serta video pembelajaran berbeda dengan modul cetak (Fausih \& Danang, 2014), sehingga peserta didik dituntut untuk belajar memecahkan masalah menggunakan caranya sendiri (Santosa, Santyadiputra, \& Divayana, 2017).

Solusi yang dapat dilakukan juga untuk mengatasi masalah tersebut adalah dengan menggunakan model pembelajaran yang sesuai dengan kondisi untuk memperbaiki pemahaman peserta didik (Irwandani \& Rofiah, 2015). PBL (Problem Based Learning) salah satu model pembelajaran yang terdapat berbagai masalah kehidupan yang dihadapi oleh peserta didik dan mengutamakan permasalahan dalam pembelajaran (Maskur, 2019). Pembelajaran berbasis masalah mendorong peserta didik untuk berpikir dan memecahkan masalah (Cotton, 2011). PBL cocok digunakan di dalam bahan ajar seperti (e-modul) modul elektronik karena PBL dalam pemecahan masalah cukup bagus untuk memahami isi pembelajaran serta dapat membantu peserta didik untuk memahami masalah dalam kehidupan sehari-hari serta bertanggung jawab atas pembelajarannya sendiri dan membantu peserta didik mengembangkan pengetahuannya (Wulandari \& Herman, 2013).

Salah satu materi pelajaran fisika kelas XI SMA/MA adalah fluida statis. Materi fluida statis antara lain tekanan Hidrostatis, Hukum Pascal, Hukum Archimedes dan lain-lain. Penerapan dari fluida statis dapat dijumpai dalam kehidupan sehari-hari, yaitu dalam membuat dongkrak mobil dan membuat kapal laut. Dalam materi fluida statis mengajarkan peserta didik berpikir, menemukan dan pemecahan masalah dalam kehidupan sehari-hari berdasarkan teori dan konsep yang sesuai. Dalam memahami materi fluida statis 
peserta didik memperoleh materi dan persamaan-persamaan tanpa proses penemuan sendiri suatu konsep fisika. Jika masalah ini terus-menerus berkelanjutan, maka peserta didik tidak dapat memahami konsep yang berdampak pada peserta didik dalam memecahkan permasalahan yang berkaitan dengan masalah sehari-hari (Purnamasari, Yuliati, \& Diantoro, 2017).

Berdasarkan analisis kebutuhan yang dilakukan, permasalahan dalam pembelajarn fisika di MA Muslimat NU Palangka Raya menunjukkan betapa pentingnya pengembangan bahan ajar berupa (e-modul) modul elektronik. E-modul ini berbasis PBL yaitu e-modul di yang merujuk pada sintaks PBL (Masek \& Yamin, 2010). Melalui pengembangan (e-modul) modul elektronik berbasis PBL diharapkan peserta didik lebih mandiri dan memahami pelajaran fisika khususnya materi fluida statis. Tujuam E-modul dibuat agar peserta didik belajar mandiri tanpa atau dengan bimbingan guru sehingga setidaknya modul ini memuat komponen dasar bahan ajar yang telah disebutkan sebelumnya (Imaningtyas, Karyanto, Nurmiyati, \& Asriani, 2016). Berdasarkan analisis kebutuhan ini maka diperlukan suatu bahan untuk peserta didik belajar berupa (e-modul) modul pembelajaran elektronik yang disusun menggunakan aplikasi Flip PDF Professional yang berisi materi fluida statis berbasis PBL.

\section{SIMPULAN DAN SARAN}

Kesimpulan yang diperoleh yaitu: peserta didik membutuhkan suatu sumber belajar untuk bisa memperkuat pemahaman peserta didik terhadap materi fluida statis serta membutuhkan sumber belajar yang dapat dipahami secara mandiri. Sehingga yang cocok digunakan adalah bahan ajar e-modul berbasis PBL yang dapat memuat teks, gambar, dan video.

Untuk Penelitian selanjutnya dapat diketahui berdasarkan analisis kebutuhan bahwa perlunya suatu media berupa bahan ajar untuk peserta didik agar dapat dapat belajar mandiri, dimana pun dan kapan pun. Bahan ajar tersebut hendaknya e-modul berbasis PBL.

\section{DAFTAR PUSTAKA}

Ambarsari, D. (2016). Implementasi Pendekatan Saintifik Untuk Meningkatkan Keterampilan Mengkomunikasikan dan Prestasi Belajar IPA Siswa Kelas IV SD. Jurnal Pendidikan Guru Sekolah Dasar, V(12): 1.112-1.121. 
Andani, Dika T., \& Yulian, M. (2018). Pengembangan Bahan Ajar Electronic Book Menggunakan Software Kvisoft Flipbook Pada Materi Hukum Dasar Kimia di SMA Negeri 1 Panton Reu Aceh Barat. Jurnal IPA dan Pembelajaran IPA, 2(1): 1-6.

Arfani, Laili. (2016). Mengurai Hakikat Pendidikan, Belajar dan Pembelajaran. Jurnal PPKn \& Hukum, 11(2): 81-97.

Azhar, Khoirul., Sa'idah, Izzah. (2017). Studi Analisis Upaya Guru Akidah Akhlak Dalam Mengembangkan Potensi Nilai Moral Peserta Didik di MI Kabupaten Demak. Jurnal Al-Ta'dib, 10(2): 73-90.

Cotton, C. (2011). Problem Based Learning in Secondary Science. The Australian Journal of Science, 95: 42-43.

Depdiknas. (2008). Panduan Pengembangan Bahan Ajar. Jakarta: Direktorat Jenderal Pendidikan Dasar dan Menengah.

DiSessa, A. A. (1993). Toward an Epistemology of Physics. Cognition and Instruction, X (23): $105-225$.

Fadli, A., Suharno., \& Musadad, A. A. (2017). Deskripsi Analisis Kebutuhan Media Pembelajaran Berbasis Role Play Game Education Untuk Pembelajaran Matematika. Seminar Nasional Teknologi Pendidikan. 52-57.

Fausih, Moh., \& Danang, T. (2015). Pengembangan Media E-Modul Mata Pelajaran Produktif Pokok Bahasan "Instalasi Jaringan LAN (Local Area Network)” Untuk Siswa Kelas XI Jurusan Teknik Komputer Jaringan di SMK Negeri 1 Labang Bangkalan Madura. Jurnal Mahasiswa Teknologi Pendidikan, 5(3): 1-9.

Fitriani, Nurul., Gunawan., Sutrio. (2017). Berpikir Kreatif dalam Fisika dengan Pembelajaran Conceptual Understanding Procedures (CUPs) Berbantuan LKPD. Jurnal Pendidikan Fisika dan Teknologi, III(1): 24-33.

Hartini, T. I., \& Martin, M. (2020). Pengaruh Penggunaan Model Pembelajaran Problem Solving Sistematis terhadap Hasil Belajar Fisika Dasar 2 Materi Listrik Arus Searah pada Mahasiswa Pendidikan Fisika. SILAMPARI JURNAL PENDIDIKAN ILMU FISIKA, 2(2), 163-174.

Imaningtyas, Citra D., Karyanto, P., Nurmiyati., Asriani, L. (2016). Penerapan E-modul Berbasis Problem Based Learning Untuk Meningkatkan Literasi Sains dan Mengurangi Miskonsepsi Pada Materi Ekologi Siswa Kelas X MIA 6 SMAN 1 Karanganom Tahun Pelajaran 2014/2015. BIOEDUKASI, 9(1): 4-10. 
Irwandani., \& Rofiah, Sani. (2015). Pengaruh Model Pembelajaran Generatif Terhadap Pemahaman Konsep Fisika Pokok Bahasan Bunyi Peserta Didik MTS Al-Hikmah Bandar Lampung. Jurnal Ilmiah Pendidikan Fisika Al-Biruni, 4(2): 165-177.

Maskur. (2019). Problem Based Learning Pada Mata Pelajaran Fiqh di Madrasah Ibtidiyah. MAGISTRA, 10(1): 97-112.103.

Masek, A., \& Yamin, S. (2010). Problem Based Learning: A Collection from the literature. Journal of Asian Social Science, 6(8): 148-158.

Miswati, M., Amin, A., \& Lovisia, E. (2020). Pengembangan Media Pembelajaran Power Point Macro Berbasis Problem Based Learning Materi Besaran dan Pengukuran Sebagai Sumber Belajar Siswa Kelas X. SILAMPARI JURNAL PENDIDIKAN ILMU FISIKA, 2(2), 77-91.

Nurcahyono, M. R., \& Kustijono, R. (2019). Keefektifan Penggunaan E-book Untuk Melatih Keterampilan Berpikir Kritis Siswa SMA. Prosiding Seminar Nasional Fisika (SNF), 3: 133-38

Purnamasari, I., Yuliati, L., \& Diantoro, M. (2017). Analisis Kemampuan Pemecahan Masalah Fisika Pada Materi Fluida Statis. Prosiding Seminar Pendidikan IPA, 2(1): 191-195.

Purwoko, Riawan Y., Nugraheni, P., Nadhilah, S. (2020). Analisis Kebutuhan Pengembangan E-modul Berbasis Etnomatematika Produk Budaya Jawa Tengah. Jurnal Mercumatika: Jurnal Penelitian Matematika dan Pendidikan Matematika, 5(1): 1-8.

Ristanto, Rizhal H. (2011). Pembelajaran Biologi Berbasis Inkuiri Terbimbing dengan Multimedia dan Lingkungan Riil Terhadap Prestasi Belajar. Jurnal Education, 6(1): 5368.

Santosa, Alif Satria E., Santyadiputra, Gede S., Divayana, Dewa Gede H. (2017). Pengembangan E-modul Berbasis Model Pembelajaran Problem Based Learning Pada Mata Pelajaran Administrasi Jaringan Kelas XII Teknik Komputer Dan Jaringan Di SMK TI Bali Global Singaraja. KARMAPATI (Kumpulan Artikel Mahasiswa Pendidikan Teknik Informatika), 6(1): 62-72.

Sasmita, P. R., \& Hartoyo, Z. (2020). Pengaruh Pendekatan Pembelajaran STEM Project Based Learning terhadap Pemahaman Konsep Fisika Siswa. SILAMPARI JURNAL PENDIDIKAN ILMU FISIKA, 2(2), 136-148.

Seruni, R., Munawaroh, S., Kurniadewi, F., \& Nurjayadi, M. (2019). Pengembangan Modul Elektronik (E-modul) Biokimia Pada Materi Metabolisme Lipid Menggunakan Flip Pdf Professional. Jurnal Tadris Kimiya, 4(1): 48-56.

Sugianto, Dony et al. (2013). Modul Virtual: Multimedia Flip Book Dasar Teknologi Digital. INVOTEC, IX(2): 101-116. 
Sukiminiandari, Yunieka P., Budi, Agus S., \& Supriyati, Yetti. (2015). Pengembangan Modul Pembelajaran Fisika dengan Pendekatan Saintifik. Prosiding Seminar Nasional Fisika (E-journal), IV: 161-164.

Supriadi. (2015). Pemanfaatan Sumber Belajar Dalam Proses Pembelajaran. Lantanida Journal, 3(2): 127-139.

Trianggono, M M. (2017). Analisis Kausalitas Pemahaman Konsep dengan Kemampuan Berpikir Kreatif Siswa Pada Pemecahan Masalah Fisika. Jurnal Pendidikan Fisika dan Keilmuan, 3(1): 1-12.

Watin, E \& Rudy, Kustijono. (2017). Efektivitas penggunaan E-book dengan Flip PDF Professional untuk Melatihkan Keterampilan Proses Sains. Prosiding Seminar Nasional Fisika. 1(1): 124-129.

Wijayanto., \& Zuhri, M. S. (2014). Pengembangan E-modul Berbasis Flip Book Maker dengan Model Project Based Learning Untuk Mengembangkan Kemampuan Pemecahan Masalah Matematika. Prosiding Mathematics and Sciences Forum, 625628

Wulandari, Bekti., \& Herman, Dwi Surjono. (2013). Pengaruh Problem Based Learning Terhadap Hasil Belajar Ditinjau dari Motivasi Belajar PLC di SMK. Jurnal Pendidikan Vokasi, 3(2): 178-191. 